\title{
Dehydration-Induced Loss of Corrosion Protection Properties in Chromate Conversion Coatings on Aluminum Alloy 2024-T3
}

\author{
V. Laget, ${ }^{a}$ C. S. Jeffcoate, ${ }^{b, *}$ H. S. Isaacs, ${ }^{b, * *}$ and R. G. Buchheit ${ }^{a, *, z}$ \\ ${ }^{a}$ Department of Materials Science and Engineering, Ohio State University, Columbus, Ohio 43210, USA \\ ${ }^{b}$ Department of Applied Science, Brookhaven National Laboratory, Upton, New York 11973, USA
}

\begin{abstract}
It is well known that chromate conversion coatings (CCCs) exhibit a prompt loss in corrosion resistance when exposed to moderately elevated temperatures $\left(60-100^{\circ} \mathrm{C}\right)$. They also suffer a gradual loss in corrosion resistance due to ambient temperature exposure. To better understand the origins of losses in corrosion resistance, CCCs were formed on 99.99\% $\mathrm{Al}, 1100 \mathrm{Al}$ [Al-1.0(Fe, $\mathrm{Si}, \mathrm{Cu})]$, and 2024-T3 (Al-4.4Cu-1.5Mg-0.6Mn), exposed to elevated and ambient temperature exposures for various lengths of time, and characterized using several different methods. $\mathrm{The} \mathrm{Cr}(\mathrm{VI})$ :total $\mathrm{Cr}$ ratio in CCCs was estimated by analysis of data derived from X-ray absorption spectroscopy. Corrosion resistance was measured by electrochemical impedance spectroscopy. The evolution of shrinkage cracking was examined by environmental scanning electron microscopy. $\mathrm{Cr}(\mathrm{VI})$ leaching experiments were also carried out to characterize the effect of thermal exposure on $\mathrm{Cr}(\mathrm{VI})$ release. Thermal analysis and X-ray diffraction were conducted to characterize the temperature-dependent changes in CCCs. Results show that CCCs degrade in several distinct steps over the temperature range of 20 to $500^{\circ} \mathrm{C}$. Our findings support the longstanding notion that dehydration is the root cause for losses in corrosion resistance due to aging at ambient and low temperatures $\left(<150^{\circ} \mathrm{C}\right)$. Extended $\mathrm{X}$-ray fine structure measurements indicate a shortening in $\mathrm{Cr}(\mathrm{III})-\mathrm{Cr}(\mathrm{III})$ nearest neighbor distances upon dehydration. This is interpreted as a consolidation in the $\mathrm{Cr}(\mathrm{OH})_{3}$ backbone of the $\mathrm{CCC}$ which leads to shrinkage cracking and immobilization of $\mathrm{Cr}(\mathrm{VI})$. This finding is important because it links older observations of the effects of aging and heating on CCCs to newer interpretations of CCC formation based on inorganic polymerization. Overall, these results reveal CCCs to be highly dynamic coatings with corrosion resistance properties that vary considerably in both the short term and long term.
\end{abstract}

(c) 2003 The Electrochemical Society. [DOI: 10.1149/1.1593040] All rights reserved.

Manuscript submitted March 25, 2002; revised manuscript received March 3, 2003. Available electronically July 17, 2003.

Chromate conversion coatings (CCCs) are commonly used on all types of aluminum alloys in manufactured products ranging from aircraft to automotive components. These thin coatings $(0.1$ to 2 $\mu \mathrm{m})$ are used as stand-alone coatings for resistance to atmospheric corrosion, and as pretreatments for painting and adhesive bonding. $\mathrm{CCCs}$ consist of insoluble and sparingly soluble $\mathrm{Al}$ and $\mathrm{Cr}$ oxides, insoluble components formed by reaction with ingredients from the coating bath (such as ferricyanides), and alloying elements from the substrate. This complex layer provides barrier protection to the alloy substrate. CCCs are also electronically resistive, ${ }^{1}$ and provide corrosion protection by inhibiting the cathodic partial reaction of corrosion processes. This component of corrosion protection can vary significantly with coating age over the first $150 \mathrm{~h},{ }^{2}$ and with alloy substrate metallurgy. ${ }^{3}$ CCCs are also able to self-repair to a certain extent. ${ }^{4-7}$ This property, also known as "self-healing," originates with a reservoir of reversibly bound $\mathrm{Cr}(\mathrm{VI}),{ }^{8}$ which is concentrated at the outer regions of the coating. ${ }^{5,9,10} \mathrm{Cr}(\mathrm{VI})$ can be released to the attacking solution and migrate to locally corroding areas where it interacts and inhibits further attack. The precise action of $\mathrm{Cr}(\mathrm{VI})$ at defects is not known, but has been speculated to involve either reduction and precipitation of an insoluble $\mathrm{Al}(\mathrm{III})-\mathrm{Cr}(\mathrm{III})$ product, or absorption of $\mathrm{Cr}(\mathrm{VI})$ into hydrous alumina gel corrosion product to form a stable corrosion protective compound. ${ }^{7}$

The degree of corrosion protection provided by stand-alone CCCs changes with time and temperature. CCCs lose corrosion resistance in a matter of minutes upon exposure at temperatures greater than $60^{\circ} \mathrm{C}^{11,12}$ Corrosion resistance is lost more gradually during ambient temperature exposure. Over several years of ambient exposure, the $\mathrm{Cr}(\mathrm{VI})$ content of the coating has been observed to decay, ${ }^{13}$ although the process that causes this decay has not yet been described. The structural, chemical, and morphological changes that lead to losses in corrosion resistance have not been studied widely. But, in the studies that have been performed, coating dehydration and dehydration-induced shrinkage cracking have been cited as the root cause for loss in corrosion protection. ${ }^{2,11,12}$

\footnotetext{
* Electrochemical Society Active Member

** Electrochemical Society Fellow.

z E-mail: buchheit@mse.eng.ohio-state.edu
}

In this paper, we report on studies aimed at understanding the effects of ambient and elevated temperature exposure on CCC structure chemistry and morphology that lead to losses in corrosion resistance. To that end, $\mathrm{Cr}(\mathrm{VI})$ : $\mathrm{Cr}$ ratios and short-range structural transformations have been measured by X-ray absorption near edge spectroscopy (XANES) and X-ray absorption fine structure (EXAFS) as a function of heat-treatment at various temperatures. The capacity for self-healing has been assessed by leaching experiments, and CCC corrosion resistance has been measured by electrochemical impedance spectroscopy (EIS). Additionally, X-ray diffraction (XRD) and environmental scanning electron microscopy (ESEM) have been used to characterize morphological changes due to heating and drying.

\section{Experimental}

Coating preparation.- $\mathrm{CCCs}$ were applied to samples prepared from $99.99 \% \mathrm{Al}$ ingot, $1100 \mathrm{Al}[\mathrm{Al}-1.0(\mathrm{Fe}, \mathrm{Si}, \mathrm{Cu})]$ sheet, and $\mathrm{Al}$ 2024-T3 (Al-4.5Cu-1.5Mg-0.6Mn) sheet. With distilled water rinsing between steps, samples were cleaned in an alkaline bath $\left(\mathrm{Na}_{2} \mathrm{SiO}_{3} 32 \mathrm{~g} / \mathrm{L}, \mathrm{Na}_{2} \mathrm{CO}_{3} 48 \mathrm{~g} / \mathrm{L}\right)$ at $65^{\circ} \mathrm{C}$ for 2 min, deoxidized in a commercial Sanchem 1000 bath at $55^{\circ} \mathrm{C}$ for $3 \mathrm{~min}$, then conversion coated in an Alodine 1200 S chromating bath at room temperature for 1 to $3 \min (7.55 \mathrm{~g} / \mathrm{L}, \mathrm{pH}$ 1.6). Samples were given a final rinse and then air dried for $24 \mathrm{~h}$ before any further testing. The Alodine 1200S bath formula used in this study was chromic acid (50-60\%), fluoro-salts (30-50\%), and $\left.\mathrm{K}_{3} \mathrm{Fe}(\mathrm{CN})_{6}(10-15 \%)\right)^{7,14}$ Post-coating heat-treatments were carried out in air for 15 min at temperatures ranging from $23^{\circ}$ (room temperature) up to $500^{\circ} \mathrm{C}$.

Thermogravimetric analysis (TGA) and differential thermal analysis (DTA).- TGA and DTA were performed with a PerkinElmer model 7 thermal analyzer on powder samples obtained by carefully scraping freshly made CCCs from substrate surfaces. The temperature of CCC samples was ramped from room temperature to $550^{\circ} \mathrm{C}$ under an air flow of $20 \mathrm{~mL} / \mathrm{min}$ and a heating rate of $10^{\circ} \mathrm{C}$ $/ \mathrm{min}$. DTA measurements were background corrected. After analysis, samples were dissolved in hot acid and measured by inductively coupled plasma-optical emission spectroscopy (ICP-OES). Ratios of $\mathrm{Cr}: \mathrm{Fe}$ :Al close to 100:5:1.5 were obtained, which is in general agreement with earlier findings from X-ray photoelectron spectros- 
copy (XPS) of CCCs. ${ }^{4}$ This suggests that scraped samples were not significantly contaminated with material from the underlying Al substrate.

XRD.-XRD measurements were performed on CCC powders heated at various temperatures with a Scintag PAD V diffractometer equipped with a $\mathrm{Cu}$ source. $\mathrm{CCC}$ powders were made by scraping the coating from metal surfaces using a sharp blade.

ESEM.-ESEM imaging was performed with a Phillips Electronics model XL-30 with field emission gun. The still-wet samples were cooled to $1^{\circ} \mathrm{C}$ and maintained at a water partial pressure of $p\left(\mathrm{H}_{2} \mathrm{O}\right)=5$ Torr (liquid phase). Samples were then slowly dried by increasing temperature to $2^{\circ} \mathrm{C}$ (vapor phase), and then up to $40^{\circ} \mathrm{C}$ with a Pelletier stage. This treatment induced formation of shrinkage cracks whose development was tracked in the ESEM. During the recording, the beam was moved back and forth between two areas to avoid rehydration that occurs during imaging. Rehydration arises due to interaction of $\mathrm{H}_{2} \mathrm{O}^{+}$, formed by electron beam ionization, with the negatively charged sample surface. This interaction suppresses water loss from the coating and in turn, inhibits the evolution of surface cracking at sample temperatures at least as high as $40^{\circ} \mathrm{C}$.

$\mathrm{Cr}(\mathrm{VI})$ leaching measurements.-To examine leaching of $\mathrm{Cr}(\mathrm{VI})$ from CCCs, fresh and heat-treated coatings were contacted with 0.1 $\mathrm{M} \mathrm{NaCl}$ for $24 \mathrm{~h}(3 \mathrm{~mL}$ of solution in contact with a circular surface area of $1 \mathrm{~cm}^{2}$ ). The amount of $\mathrm{Cr}(\mathrm{VI})$ released into the solution was measured by ICP-OES.

XANES and EXAFS measurements.-Fluorescence mode XANES measurements at the Cr K-edge $\left(E_{0}=5989 \mathrm{eV}\right)$ were made at the National Synchrotron Light Source (NSLS) at Brookhaven on beam line X19A following well-established procedures for CCCs. ${ }^{5-7,14}$ The fluorescent intensity was recorded with a 13-element detector at right angles to the incoming beam and the sample tilted at $45^{\circ}$ with respect to the incident beam. Unless otherwise stated, spectra were background corrected and normalized so that the absorption coefficient, defined as fluorescent intensity over incident beam intensity, was equal to 1.0 at $E=6250 \mathrm{eV}$. A good estimation of the ratio of $\mathrm{Cr}(\mathrm{VI})$ over total $\mathrm{Cr}$ was then directly given by the height of the pre-edge peak. ${ }^{5}$

Figure 1 shows normalized XANES data from the vicinity of the $\mathrm{K} \alpha$ absorption edge for $\mathrm{Cr}$ from powders of $\mathrm{Cr}_{2} \mathrm{O}_{3}, \mathrm{Na}_{2} \mathrm{Cr}_{2} \mathrm{O}_{7}$, and a mixture of the two. The spectra are characterized by a sharp edge, and a pre-edge peak. Absorption at energies above the edge was due to all $\mathrm{Cr}$ species present in the sample, but the pre-edge peak was due only to absorption by $\mathrm{Cr}(\mathrm{VI})$. The relative $\mathrm{Cr}(\mathrm{VI})$ content of individual samples can be estimated by comparison of the pre-edge peak heights, when the absorption edge heights are normalized as described above. In the normalized spectra in Fig. 1, the relative $\mathrm{Cr}(\mathrm{VI})$ contents are evident by inspection. The $\mathrm{Cr}_{2} \mathrm{O}_{3}$ sample contained almost no $\mathrm{Cr}(\mathrm{VI}) . \mathrm{Na}_{2} \mathrm{Cr}_{2} \mathrm{O}_{7}$ is nearly pure $\mathrm{Cr}(\mathrm{VI})(96 \%)$ and the pre-edge peak height equals that of the absorption edge itself. In the mixed sample, the pre-edge peak height is commensurate with the fraction of $\mathrm{Cr}(\mathrm{VI})$ in the sample (39\% as mixed; $33 \%$ as measured).

EXAFS measurements were also performed at the $\mathrm{Cr}$ K-edge $\left(E_{0}=5989 \mathrm{eV}\right)$ on beamline X10C at NSLS. The fluorescent intensity was recorded with a 13-element Ge Canberra detector on samples tilted at $45^{\circ}$ with respect to the incident beam. $\mathrm{Cr}(\mathrm{OH})_{3} \cdot n \mathrm{H}_{2} \mathrm{O}$ powder was diluted in $\mathrm{BN}$ powder $(5 \mathrm{mg}$ in 200 $\mathrm{mg}$ ) and pressed into pellets, while CCCs were measured directly. Three scans were recorded from each sample and data treatment was performed with LASE software..$^{15}$ The pre-edge and atomic absorption backgrounds were removed by fitting respectively with a Victoreen curve and a series of third order polynomials. The extracted EXAFS oscillations were then converted in $k$-space and weighted by $k^{2}$. Finally, the magnitude of the Fourier transform was calculated using a Kaiser-Bessel window to limit edge effects.

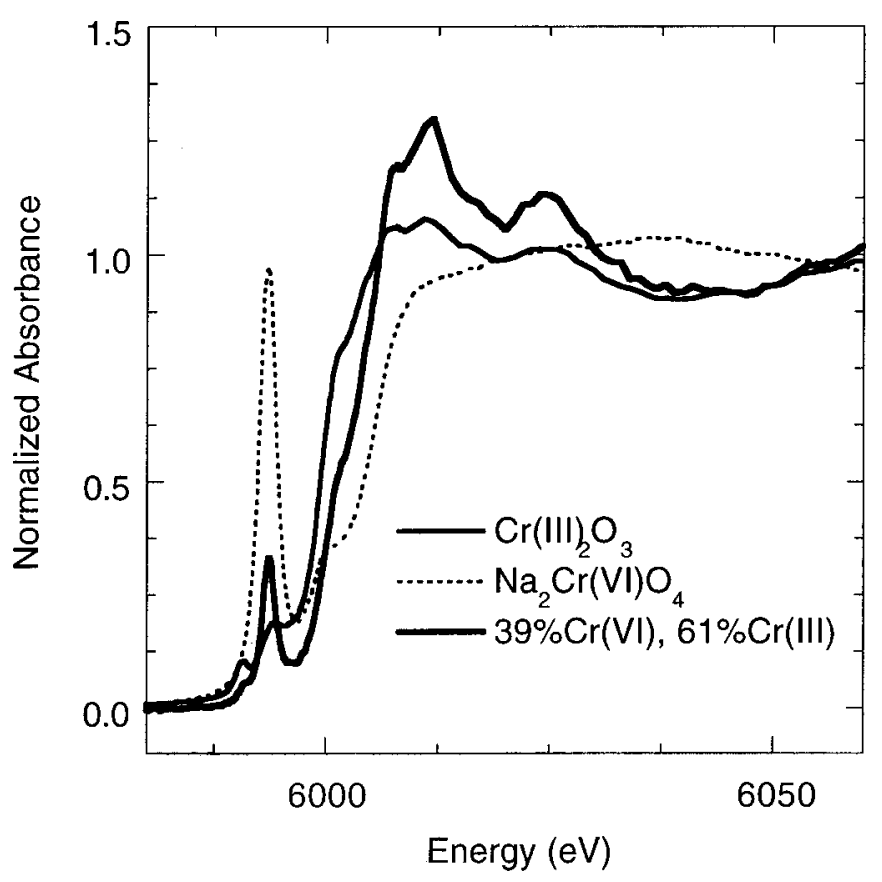

Figure 1. Normalized XANES spectra illustrating the characteristic features of the $\mathrm{Cr} \mathrm{K}$ absorption edge for $\mathrm{Cr}_{2} \mathrm{O}_{3}, \mathrm{Na}_{2} \mathrm{CrO}_{4}$, and a mixture of $\mathrm{Cr}$ (III) and $\mathrm{Cr}(\mathrm{VI})$ oxides.

These measurements were not phase corrected, so the radial distribution around the $\mathrm{Cr}$ atoms obtained by Fourier transform contains a shift of about $0.6 \AA$ toward smaller values. This shift was estimated by measuring the commercial reference $\mathrm{Cr}_{2} \mathrm{O}_{3}$ (first oxygen neighbors located at $1.99 \AA$ average ${ }^{6}$ ). The Fourier transform obtained on $\mathrm{Cr}_{2} \mathrm{O}_{3}$ is otherwise in good agreement with what has been reported elsewhere. ${ }^{16}$

Corrosion measurements.-The coating corrosion resistance, $R_{\mathrm{c}}$, was determined by EIS conducted with an EG\&G PAR 273 potentiostat coupled to a Solartron 1255 frequency response analyzer and Zplot software. Samples were exposed for $24 \mathrm{~h}$ in $\mathrm{NaCl} 0.5 \mathrm{M}$ prior to collection of the spectra. The real and imaginary components of the impedance were recorded at the open circuit potential, using a sinusoidal voltage perturbation of $10 \mathrm{mV}$ for frequencies ranging from 0.01 to $10000 \mathrm{~Hz}$. In samples where a maximum in the imaginary component of the impedance was observed, $R_{\mathrm{c}}$ was computed using a modified Kramers-Kronig transform method based on the descriptions of Kendig and Mansfeld, ${ }^{17}$ except that the integration was performed over the entire frequency domain. In samples where no maximum in the imaginary impedance was found, and as a check of $R_{\mathrm{c}}$ value determined by the method described above, $R_{\mathrm{c}}$ values were determined by equivalent circuit analysis using a simplified defective-oxide coating model. This model has been used for interpreting impedance spectra from a wide range of conversion coatings. ${ }^{18}$ Where checked, the two analysis methods yielded similar values of $R_{\mathrm{c}}$. Large values of $R_{\mathrm{c}}$ indicated small amounts of corrosion damage and were characteristic of protective coatings. Small $R_{\mathrm{c}}$ values indicated the reverse situation.

\section{Results}

Aging at ambient temperatures.-In cathodic polarization experiments, Hughes has shown that CCCs on 2024-T3 support reduction reactions at increasing rates after tens to hundreds of hours of indoor exposure. ${ }^{2}$ This indicates loss of an important component of corrosion protection due to "natural" aging. The data in Fig. 2 reflect this notion. This figure shows the coating resistance, $R_{\mathrm{c}}$, determined by EIS vs. aging time in ambient lab air. Each measurement time indi- 


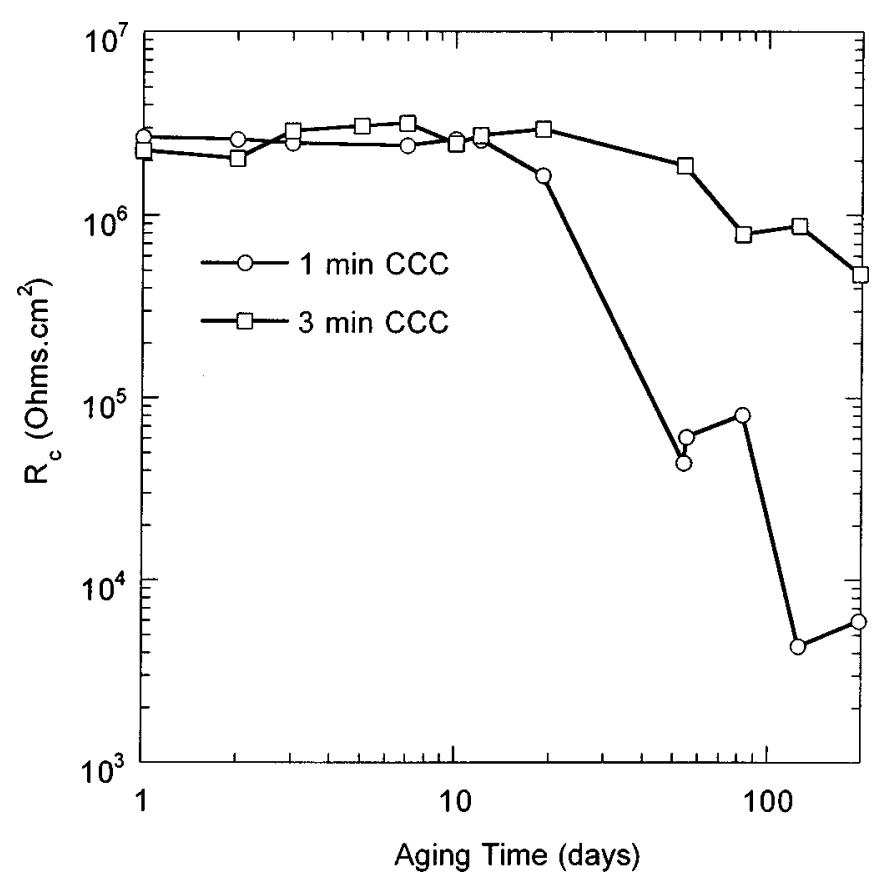

Figure 2. Corrosion resistance measured as $R_{\mathrm{c}}$ from EIS experiments determined after aging in air.

cates the length of ambient exposure. After ambient exposure, samples were immersed in aerated $0.5 \mathrm{M} \mathrm{NaCl}$ for $24 \mathrm{~h}$. EIS spectra were then collected and analyzed to determine $R_{\mathrm{c}}$. Data from CCCs formed by $1 \mathrm{~min}$ and $3 \mathrm{~min}$ immersion in the coating bath are presented. Initially, both coatings exhibited $R_{\mathrm{c}}$ values of about $2 \mathrm{M} \Omega$ $\mathrm{cm}^{2}$, which is characteristic of good quality CCCs on 2024-T3 in this test. ${ }^{18}$ Both coatings retained corrosion resistance for about 20 days after coating formation, but then exhibited significant losses. The loss in corrosion resistance was not as prompt as suggested by Hughes' data, but the 1 min CCC lost corrosion resistance more quickly than did the $3 \mathrm{~min}$ coating, and showed a corrosion resistance no better than the bare alloy after 100 days of natural aging.

Figure 3 shows data from CCCs that were aged for 5 days, 7 months, and about 16 months. These spectra were normalized between 5980 and $6600 \mathrm{eV}$. Over 7 months, there was no change in the absorption edge height outside of normal sample-to-sample variations in coating chemistry. Additionally, there was little or no reduction in $\mathrm{Cr}(\mathrm{VI})$ content in the coating. These results show that the $\mathrm{Cr}$ chemistry of CCCs was invariant over the time frame where corrosion resistance was lost as shown in Fig. 2. At longer times, 16 months, it appears that the $\mathrm{Cr}(\mathrm{VI})$ content of the coating was, in fact, reduced. This may represent the effect of a process that causes a loss in $\mathrm{Cr}(\mathrm{VI})$ component in CCCs. It has been reported that the $\mathrm{Cr}(\mathrm{VI})$ content of CCC aged in air for 7 years includes no $\mathrm{Cr}(\mathrm{VI}){ }^{13}$

ESEM.-Imaging was performed on freshly made and still-moist CCCs in order to follow the formation and evolution of shrinkage cracks during low temperature dehydration. Traditional scanning electron microscopy (SEM) requires that the sample be exposed to high vacuum. Dehydration and attendant shrinkage cracking are almost always observed in CCCs examined by SEM. ${ }^{9,13,19,20}$ In our imaging experiments performed in the ESEM, the sample was subject to pressure and temperature conditions that caused water to remain in the liquid phase just until the surface was to be imaged. To enable imaging, the temperature and pressure were adjusted to allow water to enter the vapor phase in a controlled way so that the CCC would dry slowly. Figure 4 shows a sequence of ESEM images taken as the CCC was allowed to dehydrate. Initial images showed some inhomogeneity and surface roughness, but the coating was initially uncracked. Spherical particles, noted by Arrowsmith and

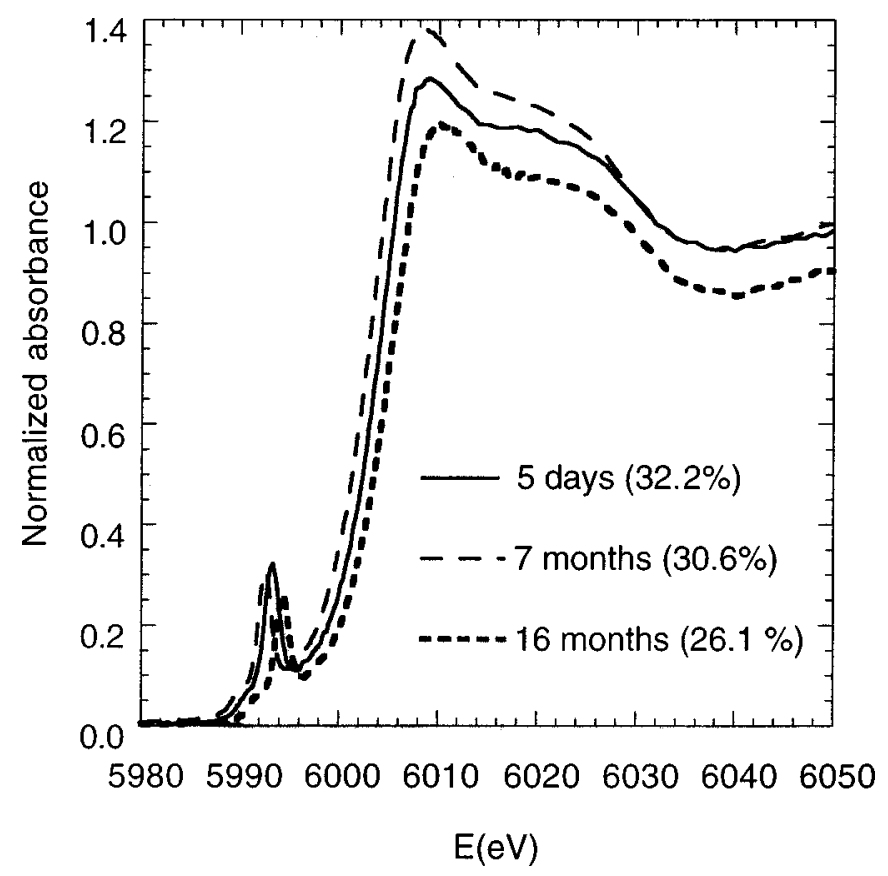

Figure 3. XANES at the Cr K absorption edge for CCCs aged in air for various lengths of time.

others ${ }^{9,19,20}$ characterized the surface morphology of the CCC. Arrowsmith describes CCCs formed from fluoride-rich coating baths as consisting of layers of spherical particles that form by precipitation and polymerization of amorphous hydrated chromium oxide. In these coatings, which were characterized by exceptionally large particle sizes, shrinkage crack paths appeared to follow boundaries formed at the intersection of spherical particles. As shown in Fig. 4, cracks in CCCs formed from the Alodine 1200S bath chemistry also seem to be associated with particle margins early in the crack formation process. Since particles sizes in Alodine 1200S coatings were relatively small, it was difficult to associate cracking with particle margins as the extent of cracking increased.

Early in the dehydration process (2-4 min), cracks appeared to be relatively superficial, and exist without penetrating the full thickness of the CCC. Shortly thereafter, a fully interconnected pattern of thin cracks emerged. Upon heating to $40^{\circ} \mathrm{C}$, no new cracking occurred, but cracks appeared to widen and deepen. These images do not reveal if the cracks exposed the substrate at their base, or if the cracks propagated laterally at the $\mathrm{CCC} /$ substrate interface.

Thermal analysis.-Figure 5 shows TGA and DTA traces of CCC powders collected from 20 to $550^{\circ} \mathrm{C}$. The compound sufferred a total weight loss of $51 \%$ in three distinct episodes. The first episode was a diffuse endothermic reaction centered at about $100^{\circ} \mathrm{C}$. This reaction was due to the loss of water ( $28 \%$ weight loss). The second episode, which occurred at about $300^{\circ} \mathrm{C}$, appeared to be very discreet and strongly exothermic. In experiments by others, a noticeable odor of $\mathrm{NH}_{3}$ and $\mathrm{HCN}$ has been reported at this temperature. ${ }^{21}$ Evolution of these gases is due to the decomposition of the ferricyanide to iron oxide. At $475^{\circ} \mathrm{C}$, a third decomposition episode is observed, which is characterized by an exothermic peak whose intensity varies from sample to sample. This transformation is associated with the formation of $\alpha-\mathrm{Cr}_{2} \mathrm{O}_{3}$, and is sometimes termed the "glow phenomenon," which refers to incandescence associated with the exothermic character of this transformation. ${ }^{22}$ This step has been shown to be very sensitive to the chemical nature of the initial chromium compound and the conditions of synthesis. ${ }^{22-24}$ Of these three reactions, the endothermic dehydration reaction centered at $100^{\circ} \mathrm{C}$ is the most technologically significant because it is in the range of service temperatures experienced by CCCs. 

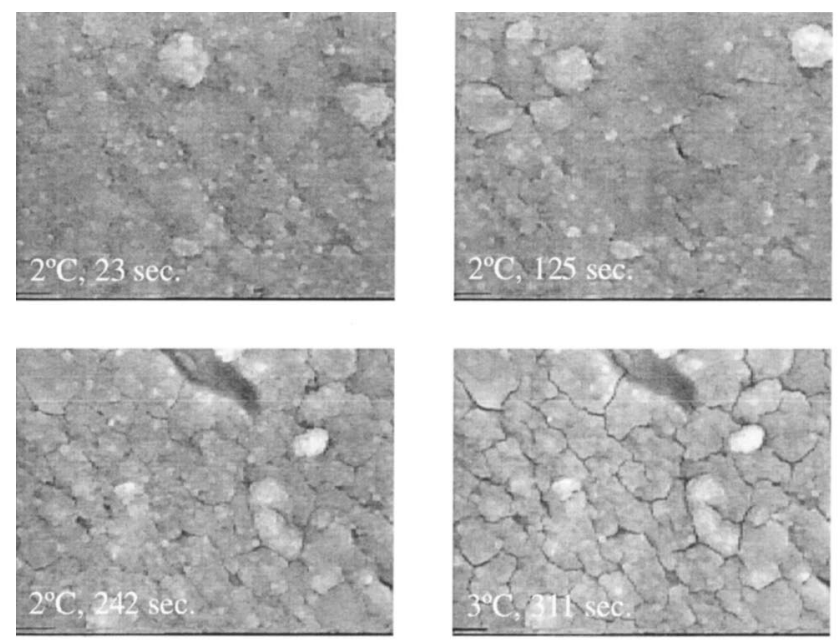

$$
p_{\mathrm{H} 2 \mathrm{O}}=5.0 \text { Torr }
$$

Thermal analysis was also performed on a CCC made according to the nominal Alodine 1200 S chemistry, but without ferricyanide. The results from this analysis are shown in Fig. 6. The DTA characteristics for episodes 1 and 3 are similar to that shown in Fig. 5, but the strongly exothermic decomposition of ferricyanide was then absent revealing a weakly endothermic dehydroxylation reaction, ${ }^{16,25}$ and an unidentified exothermic reaction at slightly higher temperatures. It is likely that dehydroxylation also occurs in the ferricyanide-bearing CCC, but the DTA signature of this process was hidden by the very exothermic ferricyanide decomposition reaction.

It is interesting that the initial composition of CCCs is often considered to comprise of one or more of the following hydrate phases: $\mathrm{Cr}_{2} \mathrm{O}_{3} \cdot n \mathrm{H}_{2} \mathrm{O}, \mathrm{CrOOH}$, or $\mathrm{Cr}(\mathrm{OH})_{3} \cdot{ }^{2,21}$ The fact that the dehydration process occurs in two clearly distinguishable steps sug-

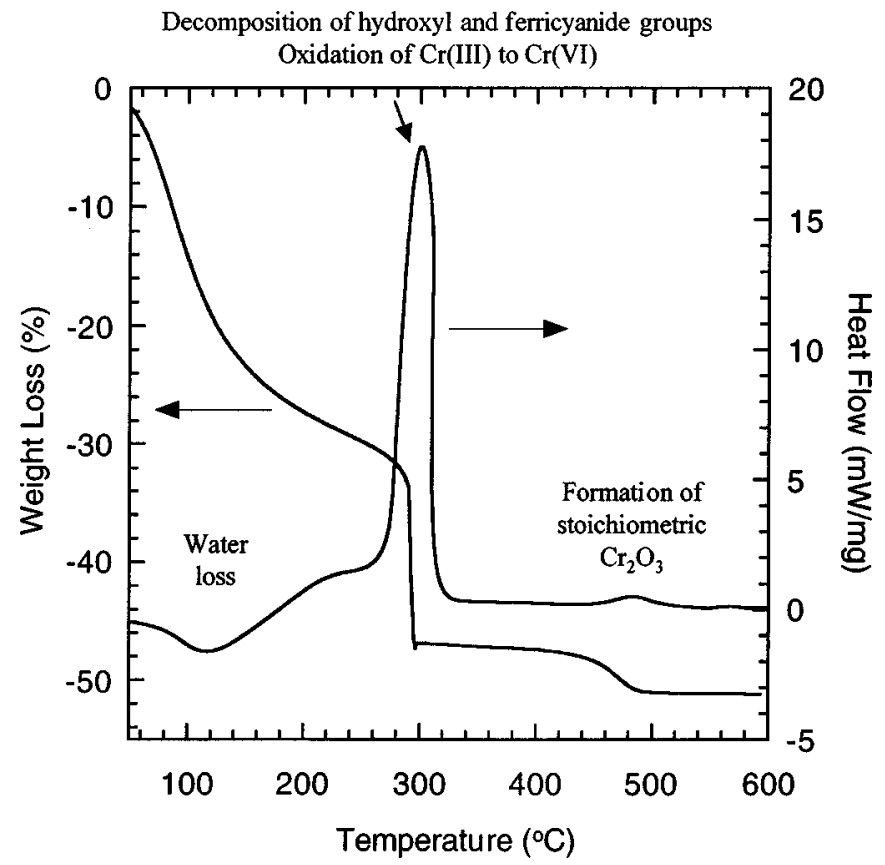

Figure 5. Data from TGA and DTA measurements from Alodine 1200S powder obtained by stripping chromate conversion coating from a 2024-T3 surface. Three distinct decomposition processes can be observed $\left(100^{\circ} \mathrm{C}\right.$, $\left.300^{\circ} \mathrm{C}, 475^{\circ} \mathrm{C}\right)$.
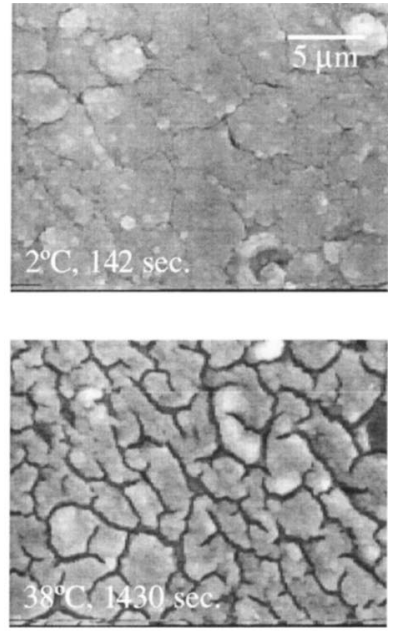

Figure 4. Crack formation during drying as observed by ESEM. Sample temperature and cumulative exposure times are indicated. gests two predominant states of hydration. These results do not indicate what hydrated phases were present, but recent studies based on Raman spectroscopy suggest that $\mathrm{Cr}(\mathrm{III})$ in CCCs is present mainly as $\mathrm{Cr}(\mathrm{OH})_{3},{ }^{8}$ although the presence of $\mathrm{CrOOH}$ cannot be strictly excluded.

XRD. - XRD was performed on CCC powders to examine for evidence of crystallization due to thermal exposure. Results indicate that CCCs retained amorphous characteristics up to $600^{\circ} \mathrm{C}$. At this temperature, XRD indicates partial CCC crystallization with the formation of $\mathrm{Cr}_{2} \mathrm{O}_{3}$ as shown Fig. 7 .

The $\mathrm{Cr}(\mathrm{VI}): \mathrm{Cr}$ ratio, $\mathrm{Cr}$ leaching, and $\mathrm{CCC}$ corrosion resistance.-The $\mathrm{Cr}(\mathrm{VI})$ :total $\mathrm{Cr}$ ratio, the $\mathrm{Cr}$ release, and corrosion resistance are all strongly influenced by elevated temperature exposure. Examination of trends in these characteristics as a function of isothermal treatment temperature reveals much about the effect of high temperature exposure on CCC structure, chemistry, and corrosion performance.

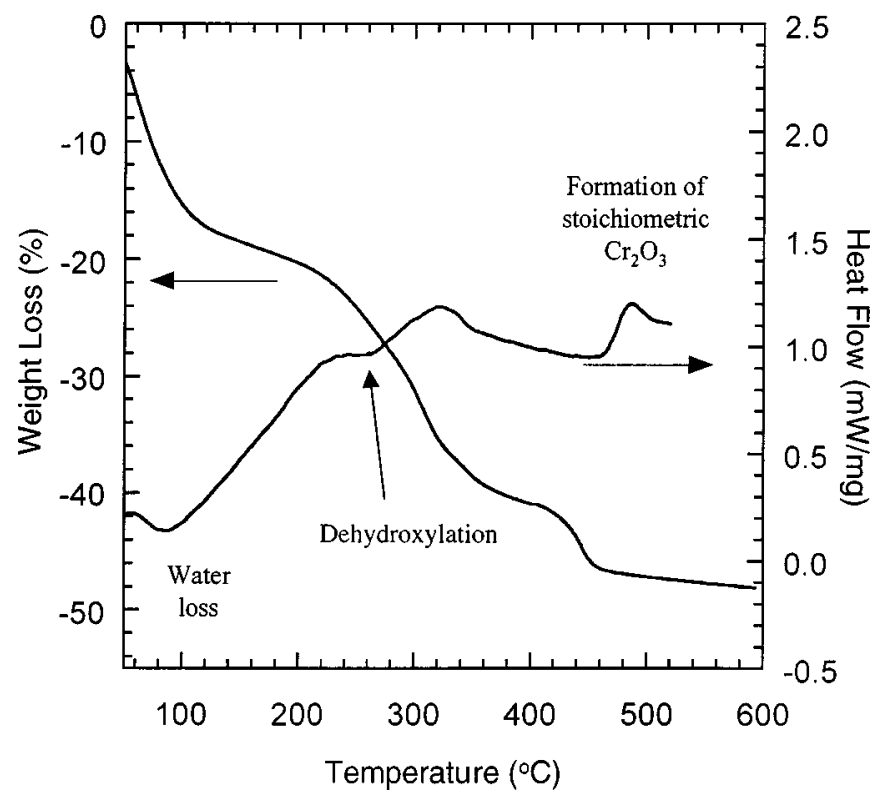

Figure 6. Data from TGA and DTA measurements from a CCC produced by a ferricyanide-free formulation that was otherwise similar to Alodine 1200S. 




Figure 7. XRD pattern from CCC powder subject to isothermal heat treatment at $600^{\circ} \mathrm{C}$ showing evidence for coating crystallization and formation of $\mathrm{Cr}_{2} \mathrm{O}_{3}$.

Figure 8 shows the variation of $\mathrm{Cr}(\mathrm{VI})$ (as $\mathrm{Cr}(\mathrm{VI})$ :total $\mathrm{Cr}$ ratio) in CCCs subject to $15 \mathrm{~min}$ isothermal heat-treatments over a wide temperature range. In these samples, the $\mathrm{Cr}(\mathrm{VI})$ :total $\mathrm{Cr}$ ratio was determined by XANES. From room temperature to $250^{\circ} \mathrm{C}$, the $\mathrm{Cr}-$ (VI): $\mathrm{Cr}$ ratio exhibited a slow and progressive decrease from 0.32 to 0.20 at $250^{\circ} \mathrm{C}$, with the majority of the decrease occurring at temperatures above $150^{\circ} \mathrm{C}$. Above $250^{\circ} \mathrm{C}$, the $\mathrm{Cr}(\mathrm{VI})$ :total $\mathrm{Cr}$ ratio in-

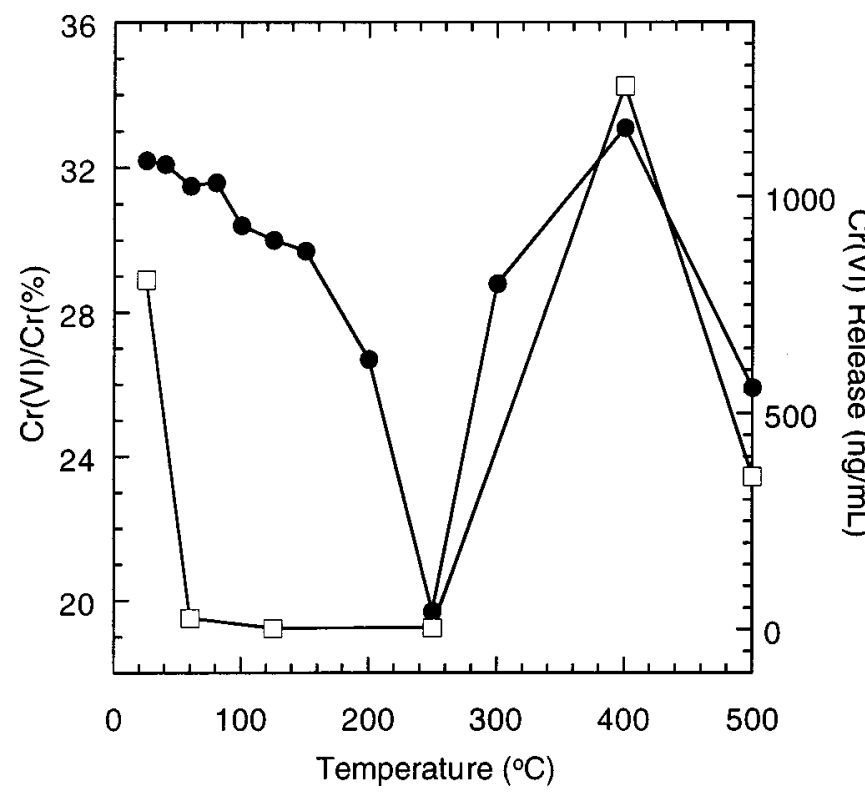

Figure 8. $\mathrm{Cr}(\mathrm{VI})$ :total $\mathrm{Cr}$ ratio (circles), and $\mathrm{Cr}(\mathrm{VI})$ release into solution (squares) plotted as a function of isothermal heat-treatment temperature. creased dramatically to values in excess of 0.30 at $400^{\circ} \mathrm{C}$. Finally, the ratio decreased again, presumably as formation of $\mathrm{Cr}_{2} \mathrm{O}_{3}$ occurs.

Figure 8 also shows the variation in $\mathrm{Cr}(\mathrm{VI})$ release into solution after isothermal heat-treatment. Cr release is almost completely suppressed by isothermal treatment between 60 and $250^{\circ} \mathrm{C}$. Because the $\mathrm{Cr}(\mathrm{VI})$ content of the $\mathrm{CCCs}$ remained relatively high $(0.25$ at $\left.100^{\circ} \mathrm{C}\right)$, it appears that dehydration immobilized the otherwise soluble $\mathrm{Cr}(\mathrm{VI})$ making it unavailable to participate in self-healing. CCCs heat-treated at temperatures greater than $250^{\circ} \mathrm{C}$ did release $\mathrm{Cr}(\mathrm{VI})$. Between 250 and $300^{\circ} \mathrm{C}$, profound chemical changes occurred in CCCs. Both $\mathrm{Cr}(\mathrm{VI})$ content and $\mathrm{Cr}$ release capacity increased sharply. At the most elevated temperatures examined, the $\mathrm{Cr}(\mathrm{VI})$ content and $\mathrm{Cr}$ release were again diminished as $\mathrm{Cr}_{2} \mathrm{O}_{3}$ was formed.

The effect of isothermal treatment on $\mathrm{Cr}$ leaching is easily detected by visual inspection of samples exposed to solution as shown in Fig. 9. After contact with solution, samples exposed at room temperature and at $400^{\circ} \mathrm{C}$ lose the golden brown color characteristic of CCCs. These samples leached $\mathrm{Cr}(\mathrm{VI})$ at levels of 800 and 1000 $\mathrm{ng} / \mathrm{mL}$, respectively, as determined by ICP-OES of solutions in contact with the coatings. By contrast, samples aged at temperatures between 60 and $250^{\circ} \mathrm{C}$ showed no lightening after exposure to solution. These CCCs released $\mathrm{Cr}(\mathrm{VI})$ at levels so low, that $\mathrm{Cr}(\mathrm{VI})$ was not detectable in solution. The sample aged at $500^{\circ} \mathrm{C}$ represented an intermediate case. There was a slight visual indication of leaching after contact with solution and the total extent of release was measured to be about $400 \mathrm{ng} / \mathrm{mL}$.

The variation of corrosion resistance and $\mathrm{Cr}(\mathrm{VI})$ release with treatment temperature is shown in Fig. 10. The variation in the two trends is remarkably coincident, though not precisely identical, and not necessary causal across the temperature range studied. At $60^{\circ} \mathrm{C}$, $\mathrm{Cr}(\mathrm{VI})$ release diminished significantly, but CCC corrosion resistance remained high. Eventually, at $80^{\circ} \mathrm{C}, \mathrm{CCC}$ corrosion resistance was lost. Here, the $R_{\mathrm{c}}$ values were as low as those observed for the untreated $\mathrm{Al}$ alloys. ${ }^{18}{ }^{\mathrm{c}}$ This may reflect a loss in passive barrier protection due to the presence of shrinkage cracks. Between 250 and $500^{\circ} \mathrm{C}$, there is again a strong correlation between the CCC corrosion resistance and $\mathrm{Cr}(\mathrm{VI})$ release. In this temperature range, the shrinkage crack structure was probably stable and the increase in corrosion resistance more nearly reflected inhibition by $\mathrm{Cr}(\mathrm{VI})$, which is again leachable after treatment at elevated temperatures, or healing of shrinkage cracks at their base by thermal oxidation.

EXAFS studies of CCCs and amorphous $\mathrm{Cr}(\mathrm{OH})_{3}$. $n \mathrm{H}_{2} \mathrm{O}$.- EXAFS studies of CCCs aged up to $20 \mathrm{~h}$ have been carried out by Vasquez et $a l .{ }^{26}$ In this study, we used EXAFS to study short range structural rearrangement occurring over much longer periods of time. EXAFS measurements were performed in an attempt to obtain structural information on the first several shells of atoms surrounding the $\mathrm{Cr}$ atoms, and on any possible structural rearrangements due to dehydration of the $\mathrm{Cr}(\mathrm{OH})_{3} \cdot 3 \mathrm{H}_{2} \mathrm{O}$ CCC backbone. ${ }^{8}$

The Fourier-transformed EXAFS data obtained from an asformed CCC is shown Fig. 11. As expected for an amorphous material, long-range structural information is absent. In the CCC sample exposed at room temperature, there are only two analyzable peaks. The first large peak (peak A) is associated with the first shell of 6 oxygen atoms around octahedrally coordinated $\mathrm{Cr}(\mathrm{III})$. The second peak (peak $\mathrm{B}$ ) corresponds to the $\mathrm{Cr}-\mathrm{Cr}$ nearest neighbor distance. The first shell of four oxygen atoms surrounding $\mathrm{Cr}(\mathrm{VI})$ are expected at distances shorter than that for peak $\mathrm{A}$ and cannot be detected in these data. For the CCC samples subjected to moderate heating treatments during 15 min, peak B seemed to diminish. However a new peak (peak B') was detected which intensified with increasing temperature.

Very similar results were obtained in EXAFS data collected from amorphous $\mathrm{Cr}(\mathrm{OH})_{3} \cdot n \mathrm{H}_{2} \mathrm{O}$ as shown in Fig. 12. Data are shown for powder samples at room temperature, aged at $50^{\circ} \mathrm{C}$ for $1 \mathrm{~h}$, and $110^{\circ} \mathrm{C}$ for $12 \mathrm{~h}$. In the first case, peaks corresponding to the first oxygen shell and $\mathrm{Cr}-\mathrm{Cr}$ nearest neighbors can also be distinguished 


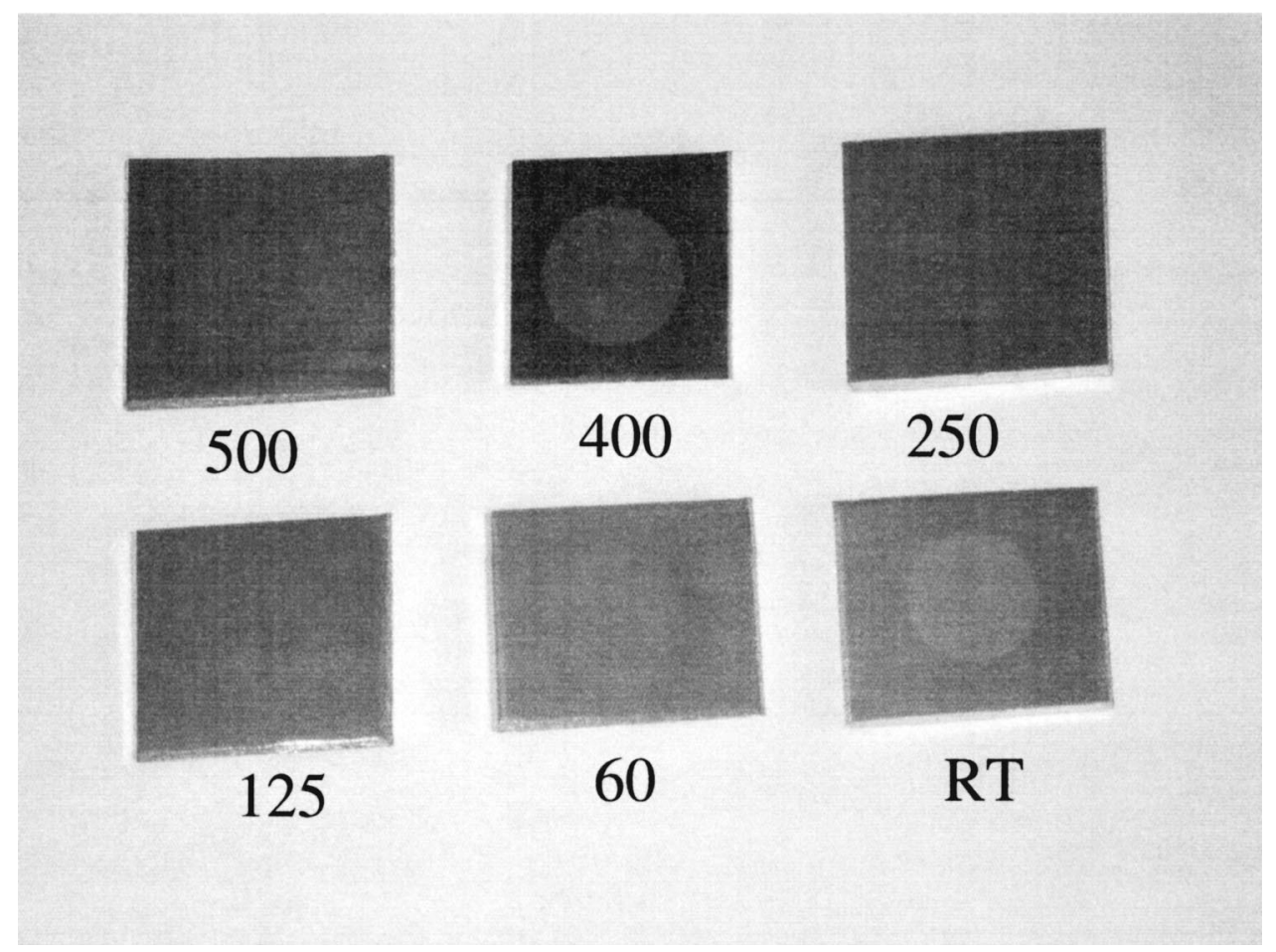

Figure 9. Optical micrographs of CCC samples subject to isothermal heattreatment at the indicated temperatures $\left({ }^{\circ} \mathrm{C}\right)$, then exposed to $\mathrm{NaCl} 0.1 \mathrm{M}$ solution. The light circular regions in the center of some of the samples indicates where $\mathrm{Cr}(\mathrm{VI})$ leaching occurred (most notable in the room temperature and $400^{\circ} \mathrm{C}$ samples). (peaks A and B). As with the CCC sample, the $\mathrm{Cr}$-Cr nearest neighbor peak seems to disappear with temperature and is replaced by a new peak, which occurs at shorter distance (peak B'). The EXAFS data for the sample aged at $110^{\circ} \mathrm{C}$ indicate that there may have been structural order at distances greater than $\mathrm{Cr}$ - $\mathrm{Cr}$ nearest neighbors, but this structure has not been evaluated yet.

Note that the data in Fig. 12 are phase shifted compared to the data in Fig. 11 causing absolute peak positions to differ. However, the difference in position between peak B and peak A, and between peak B' to peak A are identical for both materials suggesting similarities in the short-range structural rearrangement in both com-

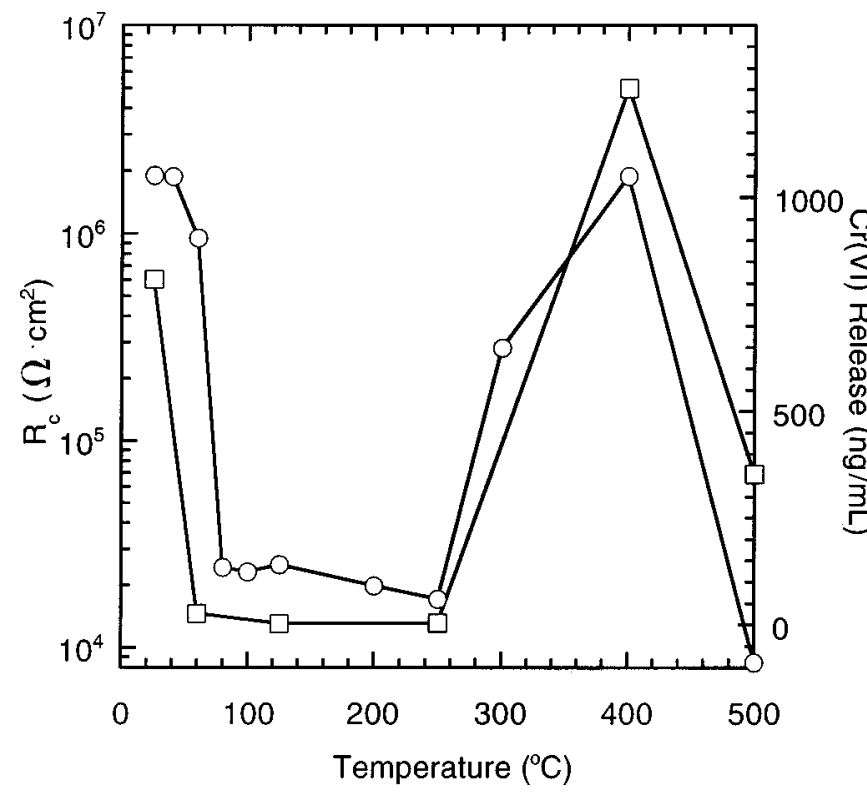

Figure 10. Variation in $(\bigcirc)$ Alodine 1200S CCC coating corrosion resistance, $R_{\mathrm{c}}$, and $(\square) \mathrm{Cr}(\mathrm{VI})$ release into solution plotted as a function of isothermal heat treatment temperature. CCCs were applied to 2024-T3 substrates by a $3 \mathrm{~min}$ immersion in the coating solution. pounds upon dehydration. On this basis, it appears that CCCs and amorphous $\mathrm{Cr}(\mathrm{OH})_{3} \cdot n \mathrm{H}_{2} \mathrm{O}$ are affected by the same structural rearrangement involving the first $\mathrm{Cr}(\mathrm{III})-\mathrm{Cr}$ (III) neighbors that move closer to each other upon thermal exposure.

This structural rearrangement may decrease the open space in the coating restricting the leachability of $\mathrm{Cr}(\mathrm{VI})$ and causing shrinkage cracking. At this point, it is not clear if this structural rearrangement is the only one associated with dehydration. Changes in the $\mathrm{Cr}(\mathrm{VI})$ -

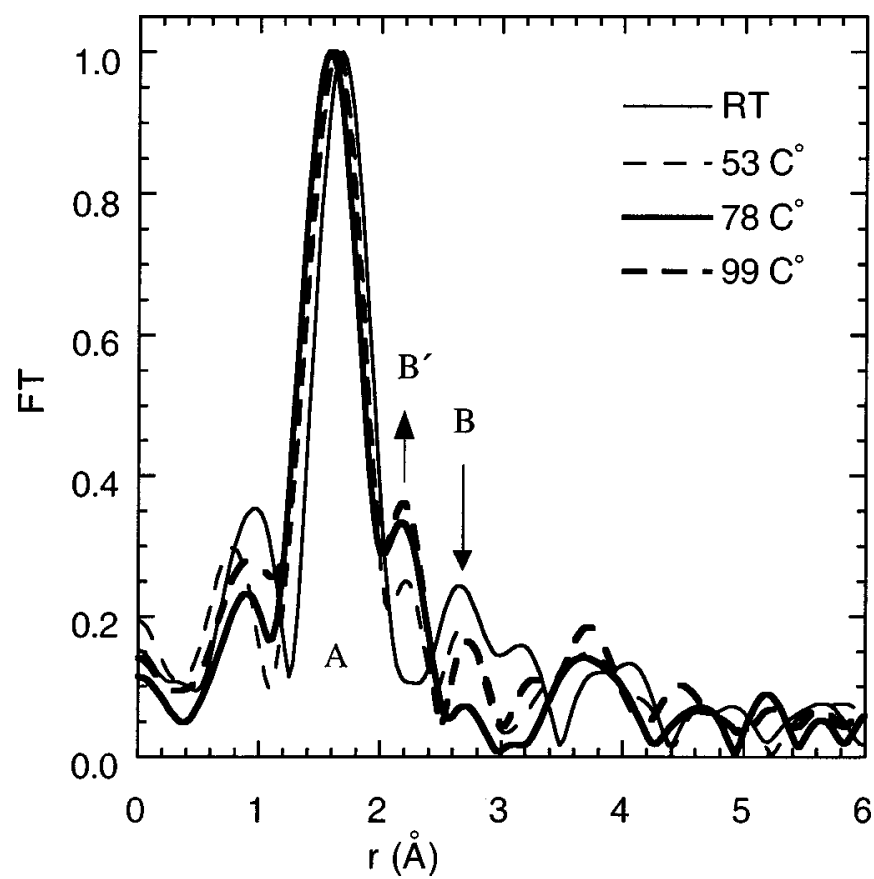

Figure 11. EXAFS data from CCCs in the as-formed condition room temperature, and after isothermal heat-treatment for $15 \mathrm{~min}$ at the indicated temperatures. 


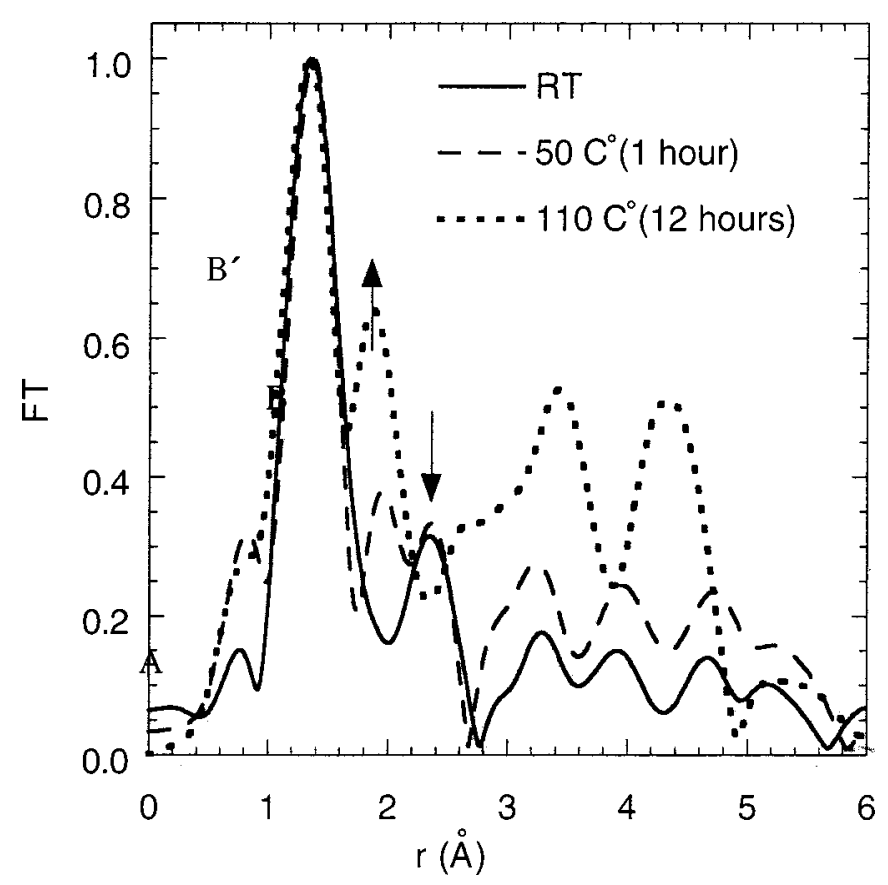

Figure 12. EXAFS data from amorphous $\mathrm{Cr}(\mathrm{OH})_{3} \cdot 3 \mathrm{H}_{2} \mathrm{O}$ in the asformed (room temperature) and heat-treated conditions. The diagram schematically illustrates rearrangement of corner-sharing to edge sharing octahedral units enabled by loss of a water molecule at a corner.

O-Cr(III) bond that directly affects chromate release have not been observed in our analysis.

\section{Discussion}

Structural rearrangement due to dehydration.-Evidence in this and earlier studies points to the importance of dehydration in the loss of self-healing with temperature and time. For example, Gallacio has shown that loss of corrosion resistance occurs under salt fog testing at temperatures in excess of $75^{\circ} \mathrm{C}^{11}$ At the same tempera- tures, a dramatic decrease was observed in the amount of $\mathrm{Cr}(\mathrm{VI})$ released in solution. More recently, using quantitative UV-visible spectroscopy, Xia et al. observed a decrease of the release of $\mathrm{Cr}(\mathrm{VI})$ in solution for both $\mathrm{CCC}$ and a synthetic $\mathrm{Cr}(\mathrm{III})-\mathrm{Cr}(\mathrm{VI})$ mixed-oxide reference powder on heating. ${ }^{27}$ Effects of long term aging $(>24 \mathrm{~h})$ under ambient conditions are less clear, but it is generally believed than corrosion resistance slowly degrades with time., ${ }^{2,27}$ Using radioactive techniques, Glass has shown that the amount of $\mathrm{Cr}(\mathrm{VI})$ released in solution decreases by a factor of 10 in one month. ${ }^{12}$ Conversely, CCCs resist the effects of aging if they are covered by an impermeable organic covering, which inhibits dehydration, or if aging is carried out in $100^{\circ} \mathrm{C}$ steam. ${ }^{12}$ The results of the present study are generally in line with these earlier findings, and taken all together point to the loss of water and not thermal exposure, in itself, as the primary element in the CCC degradation.

In order to understand the structural changes induced by dehydration that lead to losses in CCC properties, it is useful to consider the structural model of freshly formed CCCs recently described by $\mathrm{Xia}$ and McCreery. ${ }^{8}$ They describe CCC formation process as a sequential hydrolysis-condensation-polymerization reaction that results in the formation of an oligomeric $\mathrm{Cr}(\mathrm{OH})_{3} \cdot 3 \mathrm{H}_{2} \mathrm{O}$ gel. In the gel, $\mathrm{Cr}(\mathrm{III})$ centers are octahedrally coordinated by hydroxyl groups and water. During condensation and polymerization, $\mathrm{Cr}(\mathrm{III})$ octahedra are joined by - $\mathrm{OH}$ - linkages at octahedra corners as suggested by the first step in reaction scheme shown in Fig. 13. Hydrated Cr(III) gels readily dehydrate forming two -O- linkages between $\mathrm{Cr}(\mathrm{III})$ centers replacing a single -OH- linkage (Fig. 13) ${ }^{28}$ As this occurs, an increasing number of neighboring $\mathrm{Cr}(\mathrm{III})$ octahedra share edges rather than corners. Consolidation in the gel due to a corner- to edge-sharing reconfiguration is supported by the EXAFS data for the $\mathrm{CCC}$ and $\mathrm{Cr}(\mathrm{OH})_{3} \cdot 3 \mathrm{H}_{2} \mathrm{O}$ materials in Fig. 11 and 12, which show a decrease in the $\mathrm{Cr}(\mathrm{III})-\mathrm{Cr}(\mathrm{III})$ nearest neighbor distances due to isothermal treatment. Such a rearrangement would a help account for the hardening CCCs exhibit as they age. The compaction in the gel associated with the reconfiguration may lead to the development of tensile stresses in the coating and the occurrence of shrinkage cracks. The apparent immobilization of $\mathrm{Cr}(\mathrm{VI})$ by dehydration in the temperature range of 60 to $250^{\circ} \mathrm{C}$ may be related to a decrease in "open" space in the consolidated gel with a concomitant decrease chemical transport. It may also be related to a dehydration-induced

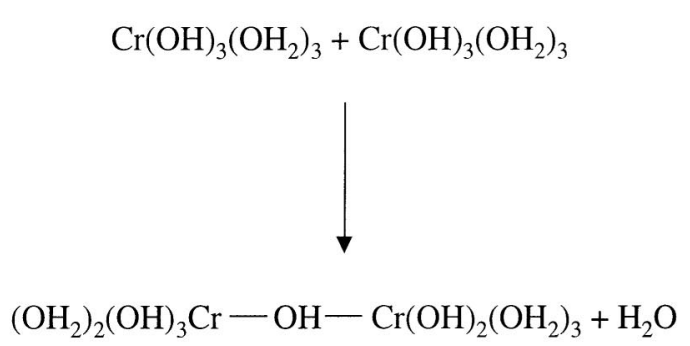

$\downarrow$

$\left(\mathrm{OH}_{2}\right)_{2}(\mathrm{OH})_{2} \mathrm{Cr}>\mathrm{O}>\mathrm{Cr}(\mathrm{OH})_{2}\left(\mathrm{OH}_{2}\right)+2 \mathrm{H}_{2} \mathrm{O}$
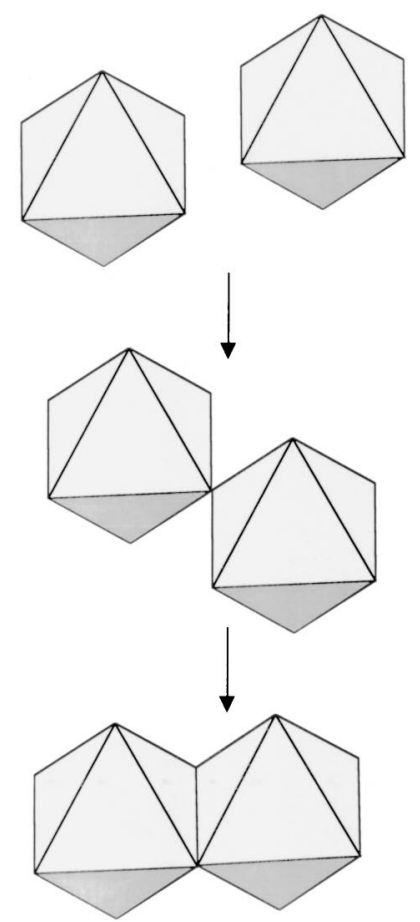

Figure 13. Condensation and dehydration reactions in $\mathrm{Cr}(\mathrm{OH})_{3}$. 
change in the $\mathrm{Cr}(\mathrm{VI})-\mathrm{O}-\mathrm{Cr}(\mathrm{III})$ bonding itself, but previous studies seem to suggest that the first hypothesis is more likely. EXAFS measurements showed structural changes occurring to CCC with dehydration leading to a more compact structure with closer $\mathrm{Cr}(\mathrm{III})$ $\mathrm{Cr}$ (III) bonds. ${ }^{23}$ Additionally, a band corresponding to a $\mathrm{Cr}(\mathrm{III})-\mathrm{O}-$ $\mathrm{Cr}(\mathrm{VI})$ covalent bond has been observed with Raman spectroscopy and remains unchanged under thermal treatment. ${ }^{8,27}$

Thermal decomposition at temperatures greater than $250^{\circ} \mathrm{C}$.- The thermal decomposition of CCCs observed in Fig. 5 and 6 is characterized by three distinct episodes, which have marked effects on coating corrosion protection properties. As has been discussed, at temperatures between 60 and $100^{\circ} \mathrm{C}$, dehydration occurs, $\mathrm{Cr}(\mathrm{VI})$ release stops, and a significant amount of corrosion resistance is lost (Fig. 7). The second transition, occurring at $300^{\circ} \mathrm{C}$, is more complex and with at least three reactions occurring over a very narrow temperature range. These reactions include (1) dehydroxylation, (2) decomposition of the ferricyanide, and (3) oxidation of $\mathrm{Cr}(\mathrm{III})$ to $\mathrm{Cr}(\mathrm{VI})$ (Fig. 6). The $\mathrm{Cr}(\mathrm{III})$ to $\mathrm{Cr}(\mathrm{VI})$ oxidation reaction appears to have a large effect on CCC corrosion protection properties. Over a very narrow temperature range there is a significant increase in corrosion resistance, which occurs simultaneously with an increase in the extent of $\mathrm{Cr}(\mathrm{VI})$ released into solution (Fig. 7). The thermal oxidation of $\mathrm{Cr}(\mathrm{III})$ to $\mathrm{Cr}(\mathrm{VI})$ is a surface phenomenon well known from work on chromium-based catalysts. ${ }^{2,24,25,29} \mathrm{Al}-$ though the exact nature of the intermediate compounds formed in this process has not been clearly established, formation of a mixed valency (III and VI) oxide such as the chromium chromate $\mathrm{Cr}_{2}\left(\mathrm{CrO}_{4}\right)_{3}$ has been suggested. ${ }^{29}$ With the $\mathrm{Cr}(\mathrm{VI})$ :total $\mathrm{Cr}$ ratio at $400^{\circ} \mathrm{C}$ being approximately 0.30 , as much as half of the CCC may be expected to be $\mathrm{Cr}_{2}\left(\mathrm{CrO}_{4}\right)_{3}$ at the outer surface, with the remainder consisting of the nonstoichiometric $\mathrm{Cr}(\mathrm{III})$ oxide. At the highest temperatures examined in this study, $\mathrm{Cr}(\mathrm{VI})$ is slowly reduced again during formation of $\alpha-\mathrm{Cr}_{2} \mathrm{O}_{3}$. This appears to correspond to a decrease in corrosion resistance.

Relation between corrosion resistance and $\mathrm{Cr}(\mathrm{VI})$ leaching. $-R_{\mathrm{c}}$ data from EIS and $\mathrm{Cr}(\mathrm{VI})$ release shown in Fig. 10 are remarkably coincident. It is tempting to suppose that immobilization of $\mathrm{Cr}(\mathrm{VI})$ leads to a loss in self-healing ability, which is related to a decrease in measured corrosion resistance. However, the authors believe that the decrease in $R_{\mathrm{c}}$ is due to the development of shrinkage cracks in the coating, which expose the substrate. Immobilization of $\mathrm{Cr}(\mathrm{VI})$ is also believed to be associated with dehydration. However, in the 60 to $250^{\circ} \mathrm{C}$ range, the trends in $R_{\mathrm{c}}$ and $\mathrm{Cr}(\mathrm{VI})$ release are believed to be coincident only.

At temperatures greater than $250^{\circ} \mathrm{C}$, the relationship may in fact be casual. In this case, a mature pattern of shrinkage cracks develops. Thermal oxidation produces $\mathrm{Cr}(\mathrm{VI})$ in the surface of the CCC. $\mathrm{Cr}(\mathrm{VI})$ can leach and heal the shrinkage cracks resulting in a repaired coating. However, above $250^{\circ} \mathrm{C}$, while the cracks remain in the CCC, corrosion resistance is regained just when $\mathrm{Cr}(\mathrm{VI})$ release is again detected. At these temperatures, $\mathrm{Cr}(\mathrm{VI})$ may be released by dissolution of $\mathrm{Cr}_{2}\left(\mathrm{CrO}_{4}\right)_{3}$ that is located in the outer part of the coating. This $\mathrm{Cr}(\mathrm{VI})$ may be acting to heal shrinkage cracks and restore high corrosion resistance. These results are significant for two reasons. First, they show that EIS is a more sensitive indicator of self-healing than originally thought, especially when the passive corrosion protection is low. Second, there may be methods based on simple thermal treatment for rehabilitating active corrosion protection in CCCs that is lost by natural aging.

\section{Conclusions}

Our results support the previously established idea that dehydration is the primary factor inducing degradation of CCCs and loss of corrosion protection in technologically significant temperature ranges $\left(60\right.$ to $\left.250^{\circ} \mathrm{C}\right)$. The formation of shrinkage cracks, and at higher temperatures, the loss in $\mathrm{Cr}(\mathrm{VI})$ leachability directly contribute to loss in corrosion protection. By considering $(i)$ new interpretations of CCC structure, and (ii) EXAFS data of CCCs subject to isothermal treatment, it is possible to link dehydration and a short range structural rearrangement to shrinkage cracking, and loss in $\mathrm{Cr}(\mathrm{VI})$ leachability. Above $250^{\circ} \mathrm{C}$, a new and leachable $\mathrm{Cr}(\mathrm{VI})$ specie is generated which allows the CCC to regain its corrosion protection properties by forming a fresh $\mathrm{Cr}(\mathrm{III})$-based protective film on the exposed substrate.

\section{Acknowledgments}

The support of the Strategic Environmental Research and Development Program (SERDP), the Air Force Office of Scientific Research (AFOSR), and the Department of Energy (DOE) is gratefully acknowledged.

The Ohio State University Research Foundation assisted in meeting the publication costs of this article.

\section{References}

1. G. E. Pike, Electrical Properties of Alodine 1200, Unclassified Internal Memorandum, RS 5815/81/003, Sandia National Laboratories, Albuquerque, NM (1981).

2. A. E. Hughes, R. J. Taylor, and B. R. W. Hinton, Surf. Interface Anal., 25, 223 (1997).

3. G. O. Ilevbare, J. R. Scully, J. Yuan, and R. G. Kelly, Corrosion (Houston), 56, 227 (2000).

4. P. L. Hagans and C. M. Haas, in Metals Handbook, Vol. 5, p. 405, ASM International, Materials Park, OH (1994).

5. M. W. Kendig, A. J. Davenport, and H. S. Isaacs, Corros. Sci., 34, 41 (1993).

6. F. W. Lytle, R. B. Greegor, G. L. Bibbins, K. Y. Blowhowiak, R. E. Smith, and G. D. Tuss, Corros. Sci., 37, 349 (1995).

7. J. Zhao, G. Frankel, and R. L. McCreery, J. Electrochem. Soc., 145, 2258 (1998)

8. L. Xia and R. L. McCreery, J. Electrochem. Soc., 145, 3083 (1998).

9. J. A. Treverton and M. P. Amor, J. Mater. Sci., 23, 3706 (1988).

10. J. Wan, G. E. Thompson, K. Lu, and C. J. E. Smith, Physica B, 208\&209, 511 (1995).

11. A. Gallacio, F. Pearlstein, and M. R. D'Ambrosio, Met. Finish., Aug, 50 (1966).

12. A. L. Glass, Mater. Prot., July, 26 (1968).

13. C. S. Jeffcoate, H. S. Isaacs, A. J. Aldykiewicz, and M. P. Ryan, J. Electrochem. Soc., 147, 540 (2000).

14. L. Xia, Ph.D. Dissertation, Ohio State University, Columbus, OH (2000).

15. LASE, EXAFS Spectral Analysis Software, Scientific Software LURE, Orsay, France (2001), http://lure.u-psud.fr/lot_scient.htm

16. P. G. Harrison, N. C. Lloyd, W. Daniell, C. Bailey, and W. Azelee, Chem. Mater, 11, 896 (1999)

17. M. Kendig and F. Mansfeld, Corrosion (Houston), 39, 466 (1983).

18. R. G. Buchheit, M. Cunningham, H. Jensen, M. W. Kendig, and M. A. Martinez, Corrosion (Houston), 54, 61 (1998).

19. D. J. Arrowsmith, J. K. Dennis, and P. R. Sliwinski, Trans. Inst. Met. Finish., 62, 117 (1984)

20. J. A. Treverton and M. P. Amor, Trans. Inst. Met. Finish., 60, 92 (1982).

21. N. J. Newhard, Met. Finish., July, 49 (1972).

22. J. D. Carruthers, K. S. W. Sing, and J. Fenerty, Nature (London), Jan, 66 (1967).

23. V. V. Viktorov, A. A. Fotiev, and I. V. Evdokimov, Inorg. Chem., 30, 82 (1994).

24. M. I. Zaki and N. E. Fouad, Thermochim. Acta, 95, 73 (1985).

25. P. Ratnasamy and A. J. Leonard, J. Phys. Chem., 76, 1838 (1972).

26. M. J. Vasquez, G. P. Halada, and C. R. Clayton, Corrosion and Corrosion Prevention of Low Density Metals and Alloys, B. A. Shaw, R. G. Buchheit, and J. P. Mordna Editors, PV 2000-23, p. 101, The Electrochemical Society, Proceedings series, Pennington, NJ (2000).

27. L. Xia, E. Akiyama, G. Frankel, and R. McCreery, J. Electrochem. Soc., 147, 2556 (2000).

28. M. Henry, J. P. Jolivet, and J. Livage, Aqueous Chemistry or Metal Cations: Hydrolysis, Condensation and Complexation, p. 155 in Structure and Bonding, Springer-Verlag, Berlin (1992).

29. S. L. M. Schroeder, G. D. Moggridge, T. Rayment, and R. M. Lambert, J. Phys. IV, 7, C2-923 (1997). 